\title{
Literatura brasileira: dependência e libertação
}

\author{
Brazilian Literature: dependence and liberation
}

\section{Célio Antonio Sardagna}

Universidade do Estado de Santa Catarina - UDESC - Ibirama - Santa Catarina - Brasil

Centro Universitário Leonardo da Vinci - UNIASSELVI - Indaial - Santa Catarina - Brasil

Resumo: O presente artigo discute aspectos relacionados à Literatura Brasileira, na sua trajetória entre uma produção que seguia os modelos ditados pela Europa e sua busca de independência, na medida em que os autores buscaram uma autonomia, apropriando-se da realidade nacional como inspiração. Nesse sentido, procura-se compreender essa busca de autonomia à luz do conceito de entre-lugar, cunhado este por Silviano Santiago, nos anos setenta. Durante muito tempo, a literatura brasileira como também as demais literaturas latino-americanas em si - foram consideradas inferiores, por isso, marginalizadas, já que superior era considerada a literatura europeia. O grito de independência da literatura brasileira, em relação à da Europa, deu-se com o advento do Modernismo, o qual enxergou na realidade e na linguagem brasileira a fonte de expressão artístico-literária. A partir de então, concebendo o elemento nacional como fonte, a expressão literária brasileira passa a ocupar o seu lugar, a traçar seu destino.

Palavras-chave: Literatura Brasileira. Dependência. Libertação. Entre-lugar. Modernismo.

\begin{abstract}
This research discusses aspects related to Brazilian Literature, in its trajetory between a production that followed the models dictated by Europe and its quest for independence to the extent that the authors sought autonomy, appropriating the national reality as inspiration. In this way, we try to understand this search for autonomy by the concept of in-between, developed by Silviano Santiago, in the seventies. For a long time, Brazilian Literature - as well as other Latin American literature themselves - were considered inferior, because of this marginalized, whereas European literature was considered superior. The independence shout of Brazilian Literature in relation to Europe took place with the advent of Modernism, which saw in reality and Brazilian language the source of artistic and literary expression. Since then, conceiving the national element as a source, the Brazilian literary expression takes its place, tracing its destination.
\end{abstract}

Keywords: Brazilian Literature. Dependence. Liberation. In-between. Modernism. 
"Não somos europeus ou americanos do norte, mas, destituídos de cultura original, nada nos é estrangeiro, pois tudo o é. A penosa construção de nós mesmos se desenvolve na dialética rarefeita entre o não ser e o ser outro". (Paulo Emílio Salles Gomes)

A frase de Paulo Emílio Salles Gomes permite que se pense a Literatura Brasileira numa relação de quase direta dependência em relação à da Europa. Contudo, nos dias atuais, essa ideia, esse sentimento de inferioridade (poder-se-ia dizer), parece mostrar-se como algo já superado, visto que se procura ver a literatura brasileira, pelo menos ao se tomar como ponto de referência Antonio Cândido, como uma representação, aqui, em território brasileiro, da literatura portuguesa (e europeia). Este autor reflete sobre o estabelecimento do cânone nacional numa relação de criação de uma identidade nacional.

Para esta criação de identidade, ainda segundo o autor, haveria a necessidade de existência de determinadas condições, as quais criaram-se juntamente com o processo de independência do Brasil. Nesse sentido, a caminhada da literatura brasileira está atrelada à criação do estado nacional, portanto, vai de um processo de ligação com o velho continente ao estabelecimento de uma autonomia.

Isto posto, a pretensão do presente texto é a de efetuar uma caminhada pela literatura brasileira, no sentido de observar sua situação enquanto ligada à literatura europeia, a um tempo, e a vontade de estabelecer-se como nacional, a partir das ideias de modernidade. Assim, tentar-se-á discutir a produção literária brasileira, a partir da sua ligação com a Europa e sua posterior nacionalização.

Há que se pensar, em um primeiro momento, na função da literatura e suas diferentes concepções. Esta foi, desde os tempos primordiais, objeto de muitas discussões. É sabido, porém, que, nas diferentes épocas em que ela se manifesta, Ihe são atribuídas funções e naturezas diversas, em consonância com a sua realidade cultural e social,

A exemplo da concepção de literatura como uma forma de manifestação da linguagem, há autores que veem a linguagem a partir de uma ótica social, entre os quais poder-se-ia citar Roland Barthes, que a concebe como a expressão do poder social, ao qual toda a sociedade está submetida. Diz ele que "[...] esse objeto em que se inscreve o poder, desde toda eternidade humana, é a linguagem - ou, para ser mais preciso, sua expressão obrigatória: a língua." (BARTHES, 1978, p. 12). Isto posto, percebe-se que Barthes atribui à linguagem a expressão do pensamento humano, numa determinada época, ou período histórico.

Porém, no que diz respeito especificamente à literatura, diz o autor em questão que há maneiras de o ser humano libertar-se da submissão da linguagem, valendo-se, para isto, da própria língua. O crítico francês revela ainda que "[...] essa trapaça, salutar, essa esquiva [...], eu a chamo, quanto a mim: literatura." (p. 16).

Diante do exposto, percebe-se que, na ideia de Barthes, a literatura é retratada como a maneira de se utilizar a linguagem sem a sujeição ao poder, distante da escravidão das regras. Assim, o autor (escritor literário) tem a liberdade de escolha e criação das palavras e estruturas, a fim de exprimir pensamentos, emoções e ideias. Na linguagem literária, as palavras adquirem novos significados, sabor diferente. Portanto, é a palavra transformada em arte.

Entre os muitos modos de conceber a literatura, está a visão de Antonio Cândido, o qual a define como um conjunto de textos escritos (muitas vezes também fixados na oralidade), esteticamente elaborados a partir da linguagem comum, que dão conta da especificidade cultural de uma comunidade (1993, p. 25). Aqui, ao que parece, subjaz o aspecto tradição e sucessão de obras, o que englobaria a criação de um sistema literário nacional, portanto, poder-se-ia conceber, na ideia de Antonio Cândido, a existência de um cânone brasileiro, já que ele estabeleceu uma tradição literária, com autores, gêneros, com relações de dependência, inicialmente, e de autonomia, em uma etapa posterior, na história literária brasileira.

Em uma de suas obras, o crítico literário Antonio Cândido lança uma metáfora, no que concerne à literatura nacional, talvez com o fim de 
mostrar possibilidade de haver a dependência da literatura nacional em relação à literatura universal: "[...] nossa literatura é galho secundário da portuguesa, por sua vez arbusto de segunda ordem no Jardim das Musas" (1993, p. 9). Portanto, ela era considerada em um plano secundário.

Com isso, passa-se ao entendimento de que ela, a literatura brasileira, é uma continuidade, uma descendência, da literatura portuguesa e, por consequência, da europeia em geral. Diante disto, pode-se compreender que a literatura, durante 0 período colonial, é marcada pela hibridez.

A seu turno, as ideias europeias exerceram uma influência considerável no pensamento brasileiro (talvez latino-americano em geral), na medida em que o país (Brasil) e os países da America Latina no seu todo foram colônias europeias.

Diante do exposto, haveria que se pensar nos períodos literários brasileiros, entre estes os que vão da literatura de informação e se estendem durante o período colonial em si, vendo-os como um tempo em que se constituíram como "[...] um apêndice da literatura seiscento-setecentista portuguesa" (ÁVILA, 1975 , p. 30). Entenda-se, no contexto da história da literatura brasileira esse período como uma continuidade da produção literária portuguesa já que a fonte em que bebiam os autores desse tempo era a literatura portuguesa e as demais fontes europeias no seu conjunto.

Pode-se, inclusive, arriscar dizer que, nesse primeiro tempo, a expressão literária se dá segundo a voz do conquistador, já que, aqui, praticamente inexistia a tradição literária. Diante disto, Affonso Ávila, ao tratar do ciclo literário brasileiro e seu desenvolvimento, concebe a literatura brasileira dentro de três ciclos, a saber: o barroco, o romantismo e o modernismo, colocando cada período dentro de uma linguagem em curso e do modo como a realidade contextual foi expressa, em cada tempo. (1975, p. 30).

Nesse sentido, cada um dos três ciclos vale-se da linguagem e da realidade a seu modo, ou seja, o Barroco brasileiro constitui-se uma apropriação da linguagem, na medida em que, autores como
Gregório de Matos importam a estética do Barroco e conseguem aclimatá-la em solo brasileiro. A nova terra oferece a realidade para a linguagem barroca aproveitar, com vistas a uma produção literária a partir daqui. Nesse sentido, percebe-se o barroco brasileiro como um estilo não propriamente brasileiro, mas, talvez, que se manifestou no Brasil.

A seu turno, o Romantismo constitui-se um processo de posse da realidade brasileira, para ambientar aqui a linguagem importada, com suas características. O ambiente brasileiro oferecia 0 espaço para a idealização da realidade, recriando-a, reinventando-a no admirado ambiente tropical, a criação do mito da nova terra, com a heroicização do elemento nacional - o índio - na ausência de heróis, já que, no caso da Europa, que tinha os cavaleiros, a possibilidade de criação de um ambiente natural, tipicamente brasileiro, expressando, assim, o nacionalismo, o sentimento nacional, brasileiro, com "cheiro" próprio, colorido típico da nova terra, expressão local. Poder-se-ia dizer que, a partir do Romantismo, tem início o sentimento do nacionalismo, a criação do "amor à terra", a exaltação, enfim, do elemento nacional. Ainda, a respeito do Romantismo (brasileiro), pode-se dizer que se tratava de "[...] uma nova linguagem, igualmente luxuriosa para dizer a mesma coisa. Nada de verdadeiro, tudo de belo, mais arte que ciência; mais cúpula que alicerce" (HOLANDA, 1995, p. 163). Visto desse modo, o Romantismo constituiu-se, na nova terra, o estilo que se propôs à fabricação de uma realidade, pelas vias da linguagem que lhe era própria, valendo-se, porém, de uma realidade nova, via posse do novo ambiente e dos elementos que este dispunha.

Mas o projeto literário brasileiro não se firmou somente na posse da linguagem e na idealização de uma realidade, de um ambiente. Pelo contrário, era preciso pensar o Brasil por meio de sua cultura, ou seja, nas palavras de Ávila, seria preciso "[...] encontrar uma dupla radicação propositiva, um elo originário que alcança simultaneamente a primitiva apropriação barroca e a experiência aposseadora do Romantismo" (1975, p. 34). E nesse sentido, tem-se o 
Modernismo, por meio do qual a literatura vê a realidade brasileira, pensa essa realidade e reflete essa mesma realidade, ou melhor, o autor usa a linguagem em vista da transformação da realidade. Assim, o Modernismo introduz uma literatura tipicamente nacional, brasileira. É, portanto, a produção modernista a linguagem da inovação, do questionamento, um pensamento forte, que poderia expressar o que é "nosso", a atualidade.

Mais do que isso, percebe-se na linguagem modernista a criação de uma experiência em cima da realidade, a liberação da linguagem literária (outrora presa a modelos e regras), a invenção criadora por meio da linguagem, a realidade que é vista e olhada com consciência crítica, sem idealizações e exageros, o novo olhar que é posto sobre a nossa nação, agora, porém, com a devida autenticidade. E, por meio desse novo olhar, a tomada de consciência da realidade brasileira e a tecitura de uma crítica consciente.

E aqui poder-se-ia dizer que ocorreu o corte do cordão umbilical com a Europa, na medida em que se dá o rompimento com os valores que eram recebidos da tradição do velho continente, de modo que a produção literária no Brasil dependia "[...] literariamente de Portugal, de onde recebíamos, não raro, o exemplo e o tom da referida imitação" (CANDIDO, 2006, p. 119). Assim, herdava-se uma tradição, cujo modelo deveria ser seguido, ou era praxe ser seguido, pelos autores "daqui". Eis a questão da posse e da apropriação da linguagem.

Talvez, seja oportuno mencionar-se a possibilidade de ter havido uma literatura comum entre Brasil e Europa (Portugal). E, por que não se poderia dizer também que residia nesse aspecto a questão da dependência? Dependência esta de modelos, já que, talvez, era considerada deficiente uma produção própria, genuinamente brasileira. Nesse sentido, poder-se-ia ter a literatura do dominador (metrópole) considerada hierarquicamente superior - modelo - e a produção literária do dominado (colônia) inspirada no modelo da metrópole, ditada por esta, considerada a fonte e a influência, ou nas palavras de Silviano Santiago, "[...] dois produtos paralelos semelhantes, mas apresentando entre eles duas decalagens capitais, responsáveis que serão pelo processo de hierarquização e rebaixamento do produto da cultura dominada" (1982, p. 21). Não à toa, poder-se-ia falar, aqui, em continuidade às palavras de Santiago, das grandes diferenças suscitadas entre ambos (dominador e dominado/Europa e Brasil): o Brasil, culturalmente, mostrava-se mais atrasado em relação à Europa, além de ocorrer mais tardiamente a produção na colônia. Nesse sentido, o que aqui se escrevia, de certo modo, era "ditado" pelos modelos vigentes no Velho Mundo, ou ainda, as tradições literárias, na Europa, nasciam, eram divulgadas, ocorriam, para aqui chegarem quando lá já estavam em processo. Dito de um modo um tanto figurado, quando o processo já estava adulto na metrópole, ele nascia na colônia.

Até com certa coerência, poder-se-ia falar da metrópole e da colônia, no que se refere às questões relativas à influência, como uma relação de centro e periferia. A metáfora poderia ser a de um ciclone, um tornado, cuja força age a partir do centro e se dissemina para as bordas.

No centro, raio zero, está o vórtice, de onde emana a força. É uma região autônoma separada do todo, ligada ao conjunto de que faz parte. Essa seria a metrópole. Tudo o que dista do vórtice é periférico, e constitui a borda. As bordas recebem a força emanada do centro. Quanto mais distante a borda do vórtice, menor é a intensidade da força. A borda (ou periferia) constitui a colônia. O desenho, como já se demonstrou, é como que de uma série de círculos concêntricos, cuja força age mais intensamente na parte central, mas é distribuída para a região periférica - para as bordas (entendidas estas como a periferia).

A seu turno, a literatura brasileira esteve, durante muito tempo, colocada à margem, na medida em que o centro era a Europa (Portugal), que exercia sua força influenciadora sobre a colônia (margem). Vista desse modo, havia uma relação de dependência, já que a "nossa literatura" exercia seu movimento em torno do vórtice (centro), ou mais que 
isso, sempre à procura deste. O movimento da literatura brasileira era dependente do centro (Portugal), do qual emanava o movimento primeiro. Por fim, é o movimento em direção ao movimento infinito, ou seja, o centro regulador do movimento marginal era a Europa.

Nessa situação de movimento em direção ao centro, encontra-se a literatura brasileira, de modo a configurar-se esta como multiplicadora dos valores europeus. Dito de outro modo, ela expressava os valores europeus, a cultura do Velho Continente. E nesse sentido, pode-se dizer que esteve atrelada à expressão literária e cultural da Europa. Não à toa, como dito inicialmente, a literatura brasileira era como que uma ramificação da literatura desse continente. A expressão "de lá" tinha "aqui" sua continuidade. Reproduziam-se, portanto, no Novo Mundo, as características e as expressões do Velho Mundo. Nesse caso, inclua-se a América Latina em geral como reprodutora dos valores europeus, ou também, não se poderia deixar de dizer, a "nossa" literatura era cópia "daquela", como bem o mostra Silviano Santiago: "A América transforma-se em cópia, simulacro, que se quer mais e mais semelhante ao original, quando sua originalidade não se encontraria na cópia do modelo original, mas em sua origem, apagada completamente pelos conquistadores" (2000, p. 14). A cultura dominante, portanto, tinha aqui sua expressão. Aqui se repetia o que lá estava em circulação. Dito de outro modo, a produção literária latino-americana estava contaminada pelos valores europeus. Por que não dizer, a produção literária daqui vivia às custas da europeia, ou então, o que aqui se produzia configurava uma "[...] obra parasita, uma obra que se nutre de outra obra, sem nunca lhe acrescentar algo de próprio; uma obra cuja vida é limitada e precária, aprisionada que se encontra pelo brilho e pelo prestígio da fonte, do chefe de escola." (SANTIAGO, 2000, p. 18). Sozinha, então, a literatura daqui não tinha expressão própria, já que, na sua raiz, estava a expressão de lá, por isso ela era braço da europeia.

Nesse sentido, tem-se no Modernismo brasileiro a inauguração de uma nova fase para a literatura nacional; uma fase que se poderia chamar de transgressão, entendida esta no seu sentido literal: como ato de não cumprir, de não observar ordem, lei, regra; o ato de ir além da regra e da ordem. Entendese, por isso, essa nova fase como um tempo que trazia em si o caráter destruidor, uma fase de superação das formas fixas ditadas, superação e quebra em relação ao passado acadêmico

Diante disso, poder-se-ia entender o novo tempo com um período de ruptura que desejava a criação de uma literatura genuinamente nacional, atual dentro do seu tempo e que pudesse atender às exigências desse período. Os antigos modelos não tinham mais condições de competir, diante das exigências desse tempo, mesmo que houvesse quem ainda desejasse apegar-se às antigas formas, nesse caso considerados apenas imitadores. Por isso, haveria que se entender esse período de ruptura, ou de transgressão - como já mencionado - como uma maneira de atender às transformações pelas quais a sociedade como um todo estava passando, uma necessidade, enfim.

O nosso modernismo, ou o Modernismo Brasileiro, trazia em si a marca da cultura popular, como algo que deveria ser preservado, um vetor determinante para a criação da identidade nacional, puramente brasileira. Em suma, trata-se de um movimento abrasileirador da cultura. Para isso, havia necessidade premente do rompimento com as estéticas arcaicas do belo discurso, a linguagem classicizante, a eloqüência, para aderir à linguagem dos vários segmentos da sociedade, reconstruindo a cultura brasileira, discutindo o elemento nacional e popular na produção literária. De um modo geral, a nova estética literária assume uma tonalidade crítica, inclusive no que concerne às desigualdades, a exemplo dos grandes proprietários de terras, de indústrias, a burguesia, os exploradores - de um lado - os operários, a miséria, os imigrantes, os explorados - de outro.

Dentre os muitos temas, a literatura moderna valeu-se desses aspectos, dessa realidade, efetuando a partir dela reflexões, ou instigando o leitor à reflexão, a exemplo de Mario de Andrade, com 
a poesia Ode ao Burguês à qual se faz menção a seguir, e dela se tecem algumas reflexões, no intuito de melhor compreender-se o caráter crítico da estética modernista:

Eu insulto o burguês! O burguês-níquel, O burguês-burguês!

A digestão bem feita de São Paulo!

O homem-curva! O homem nádegas!

O homem que sendo francês, brasileiro, italiano,

É sempre um cauteloso pouco a pouco!

Eu insulto as aristocracias cautelosas!

Os barões lampeões! Os condes Joões! Os duques zurros!

Que vivem dentro de muros sem pulos;

E gemem sangues de alguns mil-réis fracos

Para dizerem que as filhas da senhora falam o francês

E tocam o Printemps com as unhas!

Eu insulto o burguês-funesto!

$\mathrm{O}$ indigesto feijão com toucinho, dono das tradições!

Fora os que algarismam os amanhãs!

Olha a vida dos nossos setembros!

Fará sol? Choverá? Arlequinal!

Mas à chuva dos rosais

O êxtase fará sempre Sol!

Morte à gordura!

Morte às adiposidades cerebrais!

Morte ao burguês mensal!

Ao burguês-cinema! Ao burguês-tiburil!

Padaria Suíssa! Morte viva ao Adriano!

"- Ai, filha, que te darei pelos teus anos?

- Um colar... - conto e quinhentos!!!

Mas nós morremos de fome!"

Come! Come-te a ti mesmo, oh! gelatina pasma!

Oh! purée de batatas morasis!

Oh! cabelos nas ventas! Oh! carecas!

Ódio aos temperamentos regulares!

Ódio aos relógios musculares! Morte à infâmia!

Ódio à soma! Ódio aos secos e molhados

Ódio aos sem desfalecimentos nem arrependimentos,

sempiternamente às mesmices

convencionais!

De mãos nas costas! Marco eu o compasso! Eia!

Dois a dois! Primeira posição! Marcha!

Todos para a central do meu rancor inebriante!

Ódio e insulto! Ódio e raiva! Ódio e mais ódio! Morte ao burguês de giolhos, cheirando religião e que não crê em Deus! Ódio vermelho! Ódio fecundo! Ódio cíclico!

Fora! Fu! Fora o bom burguês!
Partindo-se da forma com que o poema é apresentado, percebe-se já um tom de modernidade: versos livres, heterogeneidade das estrofes, linguagem coloquial. Além disso, é notória uma linguagem marcada pela irreverência, com tom agressivo e ao mesmo tempo humorístico. O texto procura apresentar um burguês de uma maneira quase que caricatural, de uma maneira sintética, de modo que a linearidade do texto é quebrada e apresenta cortes súbitos, ao modo de cinema.

O modo com que Andrade questiona a burguesia - o modo ferino, a agressividade e o tom irreverente - ridiculariza essa classe social, dando à arte da poesia um toque totalmente inovador, fora do convencional, ou melhor ainda, quebrando totalmente as convenções, as formas, elementos tipicamente antigos, ou seja, Mário de Andrade transgride as antigas regras, abre novas portas para uma literatura mais abrasileirada, mais "nossa".

A se ver pelo título (“Ode ao burguês"), a burguesia (objeto do poema) deveria ser enaltecida (já que isso é prerrogativa da ode), mas, ao contrário, no poema, ela é atacada, é ferida na sua dignidade, chega ser ridicularizada. "Eu insulto o burguês!" diz o poeta, posicionando-se contrariamente à burguesia. Opõe-se a ela, tentando apresentar uma classe que vive sob as aparências: "E gemem sangues de alguns mil-réis fracos/Para dizerem que as filhas da senhora falam o francês/E tocam o Printemps com as unhas!" A maneira com que Andrade coloca as palavras, os termos e faz referência à burguesia cria um ar de crítica social, apagada esta, ao mesmo tempo, pelas tonalidades cômicas que são dadas por algumas estruturas. Estas, ao mesmo tempo, possibilitam uma melhor aceitação da crítica.

De um modo geral, as escolhas lexicais efetuadas pelo poeta trazem um tom paradoxal em relação à São Paulo do século $X X$, tempo este em que teve início o Modernismo, tempo de rompimento com os modelos: a modernidade trazida de fora e convivia com a realidade do Brasil. Esse processo de transição é posto às claras no poema, no momento em que Mário de Andrade vale-se de algumas palavras francesas (purée e Printemps), além de 
palavras mais arcaicas da língua portuguesa, a exemplo de "giolho" significando joelhos.

$\mathrm{Na}$ reflexão da realidade nacional, o poeta dá mostras de uma oposição radical à classe burguesa, ao seu conforto, ao seu luxo, à sua opulência quando se encontra fechada no seu mundo -, porém, fora, na rua, está ao lado da massa popular, marcada pela pobreza, desprotegida e humilde. O poema dirige sua crítica ao rico e ignorante burguês, cuja preocupação está no dinheiro, em manter as aparências, distante da fé: "Ódio e insulto! Ódio e raiva! Ódio e mais ódio!/Morte ao burguês de giolhos,/cheirando religião e que não crê em Deus!/Ódio vermelho! Ódio fecundo! Ódio cíclico!”. O poema traz a marca da apreensão da realidade e, a partir dela, efetua reflexões. Ode ao burguês é um dos muitos exemplos que se poderia apresentar no que concerne ao desempenho da função criadora de opinião e modificadora de consciência da nova fase da literatura brasileira. Uma fase transgressiva em relação ao passado, uma fase que ela consegue ver, julgar e agir em relação à realidade nacional. Uma fase de leitura da sociedade e de busca de soluções. Uma fase de tomada de consciência do seu lugar.

O poeta, assim, consegue colocar-se nesse processo que o país estava atravessando: o fechamento de uma porta - o passado literário, marcado pela reprodução de modelos, tempo de dependência - e a abertura de uma nova porta - uma produção literária marcada pela autonomia, que refletia a realidade nacional, tempo de independência. Percebe-se, enfim, uma ânsia para a formação de uma cultura literária com base no saber brasileiro, uma linguagem brasileira que reflita a realidade brasileira. Dito de outro modo, a literatura brasileira queria seu espaço, sem ser aquele já ocupado pela literatura europeia.

Ao que parece, a proposição de mudanças como foi o caso do Modernismo brasileiro - em que se desejava uma qualidade diversa na produção da literatura, mostrou certa subversão - ou transgressão - dos princípios de expressão literária. Todavia, ao que parece, havia a vontade de inserção da literatura em um processo de identificação, conhecimento e de interpretação da realidade nacional - eis a grande característica da literatura brasileira modernista. Nisto, haveria que se compreender que o processo de criação de uma literatura tipicamente nacional não ficou somente na crítica ao passado, mas procurou "transgredir" esse modelo, rompeu as barreiras de uma linguagem que se poderia dizer "oficial", para acrescer-lhe uma tonalidade folclórica e popular.

Diante disso, haveria que se estabelecer qual era, então, o ponto em que se situava a literatura brasileira, ou melhor, o seu entre-lugar. Esse conceito foi formulado e incorporado por Silviano Santiago, em 1971, na sua obra Uma Literatura nos Trópicos. Ensaios sobre dependência cultural. Acerca dessa expressão, muito se teria a dizer como conceito, a exemplo da concepção de entre-lugar como uma lacuna transgressiva entre a origem e a destinação; o vazio gerado pelo ato de colocar em contato o que não poderia estar em contato; ou então o conceito elaborado pelo próprio Santiago, quando ele postula uma posição clandestina e indeterminada, "[...] entre o sacrifício e o jogo, entre a prisão e a transgressão, entre a submissão ao código e a agressão, entre a obediência e a rebelião, entre a assimilação e a expressão - ali, nesse lugar aparentemente vazio, seu templo e seu lugar de clandestinidade" (2000, p. 26). Esse espaço, o vazio entre o modelo europeu ditado (Portugal) e a subordinação latino-americana (Brasil), constituiria o entre-lugar da literatura brasileira, cuja tomada de consciência para gerar a quebra tem início a partir do Manifesto Antropofágico, de Oswald de Andrade, com o início do Modernismo, na semana de 1922 .

O Manifesto consegue trazer à tona um movimento que se opõe à ideia de imposição, por parte do colonizador, dos valores da cultura europeia. Andrade, em seu Manifesto Antropofágico, coloca a literatura nacional "[...] contra todos os importadores de consciência enlatada" (1990, p. 47), ou seja, em oposição aos modelos trazidos prontos, que, aqui, serviam de modelo para a produção nacional. Tratase de transgredir a norma, ou melhor, negar o modelo importado. Nas palavras de Santiago, "[...] a América Latina institui seu lugar no mapa da civilização 
ocidental, graças ao movimento de desvio da norma, ativo e destruidor, que transfigura os elementos feitos e imutáveis que os europeus exportavam para o Novo Mundo" (2000, p. 16). Os modelos, as formas fixas, as regras pré-estabelecidas não são mais bemvindas, dão lugar, sim, a uma produção autóctone, pura, genuína, que tenha a cara do Brasil, que reflita a realidade nacional.

De um modo geral, poder-se-ia dizer que essa tomada de consciência e ruptura em relação à dita cultura civilizada do europeu colonizador permite que o projeto literário brasileiro dirija suas lentes à apreensão do Brasil, com vistas a que se produza uma arte literária puramente "nossa", portanto, com a marca da autonomia. E ainda, considerando os efeitos da tomada de consciência para a libertação em relação às amarras dos modelos hegemônicos europeus, Antonio Candido (2006, p. 43) mostra que a ideia antropofágica oswaldiana pode ser concebida como "[...] uma atitude brasileira de devoração ritual dos valores europeus, a fim de superar a civilização patriarcal e capitalista, com suas normas rígidas no plano social e os seus recalques impostos, no plano psicológico." A partir disso, acredita-se, a produção literária brasileira assume seu entre-lugar, já que novos ares passam a soprar e uma tradição literária passa a ser construída, agora liberta da supremacia do estrangeiro colonizador.

Ao que parece, e mesmo para retomar a ideia de Affonso Ávila, a tônica que rege a ideia do Modernismo literário é a realidade local, sua apreensão e reflexão, em vista da transformação (1975, p. 34). Tomando isso por mote, acredita-se que, ao ser incorporada pela nova estética, a produção literária passa a repercutir no seio da sociedade, passando, assim, a ser contribuidora (ou agente) para a produção de modificações na consciência brasileira e para a resolução de certas problemáticas. Este empenho coube aos envolvidos no processo modernista (e modernizador), os intelectuais da arte em geral, aos da literatura em especial.

E aqui valeriam as reflexões de Edwuard Said, acerca do papel do intelectual. Poder-se-ia, neste espaço, fazer referência aos literatos como intelectuais, aos quais caberia ou falar de modo a agradar o público ou ainda lançar a este certos desafios. Mas, afora o público, existe a questão do poder constituído, o qual também é visado pela literatura, pela tradição literária em si. Said (2005, p. 94) mostra que um dos pontos mais críticos que envolvem o papel do intelectual reside neste ínterim, no que diz respeito à sua ação diante do poder, já que ao intelectual cabe desnudar a verdade diante do poder, de maneira a "[...] subverter o poder da autoridade". Cabe, então, dizer que a tomada de posição no meio social é prerrogativa do intelectual, já que ele tem de envolver-se com o que é justo, não pode temer prejuízos para si, e precisa arriscar a própria honra. $\mathrm{O}$ fato de defender a verdade diante da autoridade e do poder, continua Said (2005), "[...]: é pesar cuidadosamente as alternativas, escolher a certa e então representá-la de maneira inteligente, onde possa fazer o maior bem e causar a mudança correta" (p. 104). Mais adiante, o autor em questão mostra o intelectual como alguém que se ancora em valores universais, e que faz a opção de "[...] representar a verdade de forma ativa e da melhor maneira possível, ou então se permitir, passivamente, ser dirigido por uma autoridade ou um poder" (p. 121). Considerando-se, aqui, a iniciativa dos modernistas, que buscaram desatar o nó que ligava a produção literária brasileira aos modelos vigentes (ditados pelo poder - Europa), poder-se-ia considerar o trabalho desenvolvido por esses intelectuais como um empenho, no sentido de

que podemos ver e compreender mais prontamente por que os intelectuais são representativos não apenas de um movimento social subterrâneo ou de grande envergadura, mas também de um estilo de vida bastante peculiar, até irritante, e de um desempenho social que lhes é único (p. 28).

Não é de se estranhar, então, que, das palavras de Said, pode-se depreender o compromisso do intelectual, com sua palavra, no sentido de seja promovida a justiça, o conhecimento e o bem comum. E aqui vale retomar-se o caminho empreendido por aqueles que se esmeraram, no início do século XX, para que o projeto literário brasileiro assumisse uma 
posição, no caso, não estar a serviço dos modelos ditados pela metrópole.

E nesse sentido, a vontade de tomada de posição e de assumir o seu lugar, entre o ser uma reprodutora de modelos e uma cópia da produção europeia, literatura brasileira busca ser influenciadora da realidade local, considerando-se que o início do século $X X$ foi uma época em que o homem buscava politizar-se, o que requeria o engajamento com a arte (nesse caso, a literatura). Com isso, nasce um novo espírito no campo da arte e da literatura brasileira, a vontade de revolucioná-la, inclusive esteticamente, com vistas à

[...] transformação do mundo com o enfraquecimento gradativo dos grandes impérios, com a prática europeia de novos ideais políticos, a rapidez dos transportes e mil e uma outras causas internacionais bem como o desenvolvimento da consciência americana e brasileira, os progressos internos da técnica e da educação impunham a criação de um espírito novo e exigiam a reverificação e mesmo a remodelação da Inteligência Nacional. Isso foi o movimento modernista, que a Semana de Arte Moderna ficou sendo o brado coletivo principal (ANDRADE, 1978, p. 231).

Ao que parece, Mário de Andrade destaca três importantes pontos que poderiam ter contribuído para suscitar as modificações necessárias para que a literatura brasileira pudesse deixar de ser reprodutora de modelos estrangeiros. Primeiramente, poder-se-ia destacar a possibilidade de liberdade para a pesquisa estética, um segundo ponto o novo modelo criado da inteligência artística nacional e como terceiro haveria que se falar na afirmação de uma consciência criadora nacional. Tais aspectos, no que concerne à literatura, possibilitaram a afirmação da independência intelectual e da originalidade em termos de produção. Em resumo, com o modernismo literário, a "nossa" literatura tornou-se nacional e atual.

Nesse entre-lugar, ou melhor, nessa postura assumida pelo projeto literário brasileiro, caberia aos escritores incorporar esteticamente uma nova realidade, já que as antigas formas, herdadas e ditadas pelo Velho Continente passaram a não mais existir e nem poderiam dar conta das exigências modernas. Além disso, mesmo que houvesse quem ainda a elas tentasse apegar-se, estes não seriam nada mais que reprodutores de modelos ineficazes e descabidos, já que o movimento modernista brasileiro trouxe a tônica da inovação literária (e artística em geral) em um tempo que esta encontrava-se marcada pela estagnação. Moderna, então, é a literatura que nasceu desse movimento e está em conformidade com seu tempo. E seria oportuno também dizer-se que, ao assumir seu lugar entre o vazio deixado pelos modelos ditados do estrangeiro e a inspiração puramente nacional, a literatura brasileira traça seu destino como moderna e genuinamente nacional.

\section{Referências}

ANDRADE, Mário de. Aspectos da literatura brasileira. São Paulo: Livraria Martins Fontes, 1978.

ANDRADE, Oswald de. Obras Completas de Oswald de Andrade. São Paulo: Editora Globo e Secretaria de Estado da Cultura de São Paulo, Vol. 6, 1990.

AVILA, Affonso. Do Barroco ao Modernismo. IN: AVILA, Affonso (Org). O Modernismo. São Paulo: Editora Perspectiva, 1975.

BARTHES, Roland. Aula. Tradução de Leyla PerroneMoisés. São Paulo: Cultrix, 1978.

CANDIDO, Antonio. Literatura e sociedade. Rio de Janeiro: Ouro sobre Azul, 2006.

CANDIDO, Antonio. Formação da literatura brasileira. Belo Horizonte: Itatiaia, 1993.

HOLANDA, Sérgio Buarque de. Raízes do Brasil. São Paulo: Companhia das Letras, 1995.

SAID, Edwuard Wadie. Representações do intelectual. São Paulo: Companhia das Letras, 2005.

SANTIAGO, Silviano. O entre-lugar do discurso latinoamericano. In: Uma Literatura nos Trópicos. Ensaios sobre dependência cultural. Rio de Janeiro: Rocco, 2000.

SANTIAGO, Silviano. Apesar de dependente, universal. In: Vale Quanto Pesa. Ensaios sobre questões político-culturais. Rio de Janeiro: Paz e Terra, 1982. 